\section{Self-report quality of life measure for people with schizophrenia: the SQLS}

\author{
GREG WILKINSON, BERNADETTE HESDON, DIANE WILD, RON COOKSON, \\ CAROLE FARINA, VIMAL SHARMA, RAY FITZPATRICK \\ and CRISPIN JENKINSON
}

\section{Background Quality of life is the subject of growing interest and investigation.}

Aims To develop and validate a short, self-report quality of life questionnaire (the Schizophrenia Quality of Life Scale, SQLS).

Method People with schizophrenia in Liverpool were recruited via the NHS. Items, generated from in-depth interviews, were developed into an 80 item self-report questionnaire. Data were factor analysed, and a shorter form measure was tested for reliability and validity. This measure was administered together with other self-report measures - SF-36,GHQ-12 and HADS - to assess validity.

Results Datawere analysed to produce a final 30-item questionnaire, comprising three scales ('psychosocial','motivation and energy', and 'symptoms and sideeffects') addressing different SQLS dimensions. Internal consistency reliability of the scale was found to be satisfactory. There was a high level of association with relevant SF-36, GHQ-12 and HADS scores.

Conclusions The SQLS was completed within 5-10 minutes. It possesses internal reliability and construct validity, and promises to be a useful tool for the evaluation of new treatment regimes for people with schizophrenia.

Declaration of interest JanssenCilag Ltd funded the project. G.W. is Editor of The British Journal of Psychiatry.
Schizophrenia can devastate the lives of people who suffer from it and the lives of their families. People with schizophrenia suffer distress, disability, reduced productivity and lowered quality of life (QoL) (Sartorius, 1997). The development of QoL measures for use in psychiatric disorders has not progressed at the pace it has in other clinical disciplines (Hunt \& McKenna, 1993). Psychiatrists use questionnaires and schedules to determine mental state and assess treatment regimes, and such measures are designed as an adjunct to clinical interview. Quality of life instruments, on the other hand, are not designed to guide diagnosis, but are intended as measures of patient-assessed health and wellbeing, and are constructed to include issues of importance to patients. A number of instruments exist to measure health status and health-related QoL. For example, the SF-36 health survey questionnaire (Ware \& Sherbourne, 1992), the Nottingham Health Profile (Hunt et al, 1986) and the Sickness Impact Profile (Bergner et al, 1981) are all general measures of health status that can be used to assess functioning and well-being in any patient group. However, such generic measures can often overlook the QoL concerns of specific patient groups. Researchers have argued strongly for the development of a robust QoL instrument specific to schizophrenia, based on the subjective judgement of patients and including only relevant items that are expected to change (Awad et al, 1997). These authors report the dearth of reliable and validated QoL scales that are sensitive enough to detect the relatively small changes that patients experience in clinical trials. Although there are a number of measures available for the assessment of QoL in people with schizophrenia, these measures cannot be considered appropriate for evaluating interventions for the following reasons:

(a) some measures are too lengthy (over 100 items) for use in a clinical trial: e.g. the Oregon Health-Related Quality of Life Questionnaire (OQLQ; Bigelow et al, 1991), the Quality of Life Self-Report-100 (QLS-100; Skantze et al, 1992), and the Lancashire Quality of Life Profile (Oliver et al, 1996);

(b) some need to be completed by a psychiatrist or other trained interviewer, whereas a measure of QoL is dependent on subjective self-report: e.g. the Satisfaction with Life Domains Scale (Baker \& Intagliata, 1982), the Quality of Life Scale (QLS; Heinrichs et al, 1984) and Manchester Short Assessment of Quality of Life (MANSA) (Priebe, 1999);

(c) some measures take a broad view of QoL, developed for the assessment of community programmes, and were therefore considered to be unlikely to be sensitive to QoL changes resulting from clinical changes as measured in a clinical trial: e.g. the Community Adjustment Form (CAF; Stein \& Test, 1980) and the Wisconsin Quality of Life Questionnaire (Becker et al, 1993);

(d) some are limited in terms of their psychometric properties: e.g. the QLS (Heinrichs et al, 1984).

What is lacking for research and clinical purposes is a practical, brief self-report measure, developed according to standardised methodology and possessing good psychometric properties. To fill this gap, we present the results of a study illustrating the development and validation of a novel QoL measure specific to people with schizophrenia: the Schizophrenia Quality of Life Scale (SQLS).

\section{METHOD}

The 30-item SQLS (see Appendix) was developed and validated in three stages.

\section{Subjects and procedures}

\section{Stage I: Item generation}

Exploratory in-depth semi-structured interviews with 20 patients (male and female) with schizophrenia were tape-recorded and generated 378 candidate items. (The interview schedule is available from the first author upon request.) The sample size for this stage of the study was determined by the point at which no new significant themes emerged from the interviews.

People diagnosed with schizophrenia were randomly selected from two general 
practitioner lists. They were contacted by letter and those who agreed to take part were interviewed by one of the research team (B.H.). Each was asked to describe areas of life that had been influenced by their condition, and a list of these aspects was extracted from the transcribed interviews. Six researchers, including a psychiatrist and psychologists, then independently devised questionnaire items from this list. These were discussed jointly, scrutinised for repetition and ambiguity, and a final set of items was agreed by consensus. This gave a final pool of 87 items, which were drafted into a questionnaire asking about the QoL of patients over the past 7 days. (The full item pool and a list of items changed are available from the first author upon request.) The eliminated items were: "I enjoy looking after myself", "People are frightened by the way I am", "I have enough money", "I take drugs so that I can cope", "I can accept my limitations", "I feel like I fit in" and "People understand me"; "I am concerned about my sex drive" and "My sex drive has declined" were combined to give "I am concerned about my sex life".

A pilot study was undertaken on 20 people with schizophrenia recruited using the same approach. The patients were asked six open-ended questions after completing the questionnaire (responses available from the first author upon request):

(a) Did you have any problems with the wording or phrasing of the questions?

(b) Were there any particular questions which were difficult to answer?

(c) Did you have any problems with the choice of answers on the questionnaire?

(d) Did you feel there were any important issues missing from the questionnaire?

(e) Did you have any difficulty understanding or following the instructions?

(f) What was your overall impression of the questionnaire?

As a result, seven items were removed at this stage, as patients thought them ambiguous or meaningless.

The face validity of the questionnaire was agreed at this stage by a psychiatrist (G.W.), in informal consultation with psychiatrist colleagues. Consequently a long-form questionnaire was devised containing 80 items. Respondents could select a response to each question from:
'Never' (0); 'Rarely' (1), 'Sometimes' (2), 'Often' (3), or 'Always' (4).

\section{Stage 2: Item reduction and scale generation}

This phase enabled the development of a shorter and more practical instrument, and the identification of three scales addressing different dimensions of the impact of schizophrenia on quality of life.

The 80-item questionnaire was completed by individuals with schizophrenia in contact with secondary care clinics: 229 people were approached and $161(70 \%)$ agreed to take part. The mean age of respondents was 43 years $\quad$ (s.d. $=11.3$; $\min =17, \max =73, n=158$; age of two respondents not known); 105 (65\%) were male and $56(35 \%)$ female; $54(34 \%)$ were living alone, and the remainder were living with friends or relatives.

\section{Stage 3: Testing construct validity}

Statistical procedures were undertaken (documented below) to reduce the number of items and to devise a short-form instrument. The construct validity of the resulting measure was assessed by comparing results on the SQLS with those from established measures of health status (SF-36) and psychological outcome (the General Health Questionnaire (GHQ) and Hospital Anxiety and Depression Scale (HADS)).

The SQLS was administered with the SF-36, GHQ-12 (Goldberg \& Williams, 1988) and HADS (Zigmond \& Snaith, 1983) in both clinic and home-based settings. Of the 112 people with schizophrenia who were approached, $78(70 \%)$ agreed to take part. The mean age of patients was 40 years (s.d. $=11.9 ; \quad \min =18 ; \quad \max =64$, $n=78) ; 25(32 \%)$ lived alone, and the remainder lived with friends or relatives.

The SQLS was completed by almost all respondents within 5-10 minutes. The few who took longer expressed the need to think longer about their responses.

\section{Statistical procedures}

Principal components analysis was carried out on results from the 161 questionnaires obtained in Stage 2 to reduce the number of items and determine the dimensions underlying the remaining items. Internal reliability was assessed using Cronbach's $\alpha$ (Cronbach, 1951). Items were summed for each dimension and transformed onto a scale from 0 (best health status) to 100 (worst health status). Summary statistics were provided in the form of means, standard deviations and quartiles. Construct validity was assessed correlating results on the SQLS with other measures using the Spearman correlation coefficient, indicating the spread of responses and the lack of floor/ceiling effects.

\section{RESULTS}

The questionnaire was found to be acceptable to all respondents and feasible for use in a routine clinical setting.

\section{Item reduction and scale generation}

A principal components analysis was carried out on results from the 161 questionnaires obtained in Stage 2. The detailed results are available from the first author upon request. All questionnaires were scored using a Likert-type format. Three factors with item-loadings $\geqslant 0.5$ were identified, which appeared to characterise three underlying constructs: 'psychosocial', 'motivation and energy' and 'symptoms and side-effects'. These three factors, which accounted for $40.6 \%$ of the variance, were then subjected to varimax rotation. Items loading $<0.4$ on any factor were removed at this stage. It was assumed that items loading $\geqslant 0.4$ on each factor constituted a scale. Internal reliability was assessed on the items constituting each scale. Items were removed from each of the scales if they increased the $\alpha$ coefficient.

These procedures resulted in a set of 30 items incorporated in three scales:

(a) 'Psychosocial' (15 items) addresses various emotional problems, for example, feeling lonely, depressed or hopeless, as well as feelings of difficulty mixing in social situations and feeling worried about the future.

(b) 'Motivation and energy' (7 items) addresses various problems of motivation and activity, such as lacking the will to do things. Some items in this scale ask whether patients engage in positive aspects of life; these items are $13,14,16$ and 21 , and are re-coded $4=0,3=1,2=2,1=3$ and $0=4$ before the scale total is calculated.

(c) 'Symptoms and side-effects' (8 items) addresses issues such as sleep disturbance, blurred vision, dizziness, muscle twitches and dry mouth, which can be caused by medication. 


\section{Transformation of scale scores}

The purpose of the three scales is to indicate the extent of difficulty on each domain measured. Consequently, each scale score is transformed to have a range from 0 (the best status as measured on the SQLS) to 100 (the worst status as measured on the SQLS), with each scale calculated as follows: the scale score (SS) equals the total of raw scores of each item in the scale $\left(R S_{\text {tot }}\right)$, divided by the maximum possible raw score of all the items in the scale $\left(R S_{\max }\right)$, all multiplied by $100: S S=\left(R S_{\text {tot }}\right.$ l $\left.R S_{\max }\right) \times 100$. Table 1 shows the three scale scores for the sample as a whole and the distribution of the scores, indicating no floor/ceiling effects. The principal components analysis is available from the first author upon request.

\section{Internal consistency}

Table 2 shows the correlations of items with their scale totals, and the internal consistency reliability of the scales (that is, the extent to which items in a scale reflect a single underlying dimension). Items were highly correlated with their own scale score (corrected to exclude the item being correlated). Internal reliability was assessed using Cronbach's (1951) $\alpha$ statistic. All the scales show good internal consistency reliability (Nunnally \& Bernstein, 1994; Ware et al, 1994). We consider that if the $\alpha$ value is too high, this may suggest a high level of item redundancy, that is a number of items asking the same question, but in slightly different ways (Hattie, 1985; Boyle, 1991) and may indicate that some of the items are unnecessary. Nunnally (1978) suggests that $\alpha$ should be above 0.70 , but probably not higher than 0.90 .

\section{Construct validity}

Construct validity was assessed comparing results on the SF-36, GHQ-12 and HADS. We hypothesised that the SF-36 'energy' dimension would be strongly associated with SQLS 'motivation and energy' dimension, and that the SF-36 'mental health' scores would be strongly associated with the 'psychosocial' score of the SQLS. These predicted correlations were substantiated (SF-36 'energy' correlation with SQLS 'motivation and energy': $\rho=0.72$, $P<0.001, n=76$; SF-36 'mental health' correlation with SQLS 'psychosocial': $\rho=0.65, P<0.001, n=75)$. It was hypothesised that significant correlations between
Table I Schizophrenia Quality of Life Scale (SQLS) scores from the first survey of respondents

\begin{tabular}{lccc}
\hline & & Scale & \\
\cline { 2 - 4 } & Psychosocial & $\begin{array}{c}\text { Motivation } \\
\text { and energy }\end{array}$ & $\begin{array}{c}\text { Symptoms } \\
\text { and side-effects }\end{array}$ \\
\hline Mean & & 52.44 & 34.74 \\
Median & 47.74 & 53.57 & 34.38 \\
s.d. & 47.50 & 20.27 & 21.16 \\
Range of scores & 22.28 & $3.57-100$ & $0-87.5$ \\
$n$ & $0-100$ & 161 & 161 \\
\% scoring minimum & 160 & 0 & 1.3 \\
\% scoring maximum & 1.9 & 1.9 & 0 \\
25th percentile & 0.6 & 38.29 & 15.63 \\
50th percentile & 33.33 & 53.57 & 34.38 \\
75th percentile & 47.50 & 64.29 & 50.00 \\
\hline
\end{tabular}

Each scale has a range from 0 (best possible health, as measured by the scale) to 100 (worst possible health, as measured by the scale).

Table 2 Corrected item to total correlations $(\rho)$ and internal reliability (Cronbach's $\alpha$ ) of scales generated from the first survey of respondents with schizophrenia

\begin{tabular}{|c|c|c|}
\hline Scale and items & $\begin{array}{l}\text { Item to total } \\
\text { correlation, } \rho\end{array}$ & Cronbach's $\alpha$ \\
\hline Psychosocial & & 0.93 \\
\hline Worry about things & 0.66 & \\
\hline Feel very mixed up & 0.83 & \\
\hline Feelings go up and down & 0.64 & \\
\hline Concerned won't get better & 0.70 & \\
\hline Find it hard to concentrate & 0.64 & \\
\hline Feel people avoid me & 0.67 & \\
\hline Worry about future & 0.62 & \\
\hline Difficult to mix with people & 0.75 & \\
\hline Feel lonely & 0.61 & \\
\hline Take things people say the wrong way & 0.64 & \\
\hline Feel angry & 0.66 & \\
\hline Feel jumpy and edgy & 0.69 & \\
\hline Feel hopeless & 0.85 & \\
\hline Get upset thinking about the past & 0.65 & \\
\hline Feel down and depressed & 0.74 & \\
\hline Motivation and energy & & 0.78 \\
\hline Like to plan ahead & 0.60 & \\
\hline Able to carry out daily activities & 0.67 & \\
\hline Feel I can cope & 0.68 & \\
\hline Tend to stay at home and do not go out & 0.59 & \\
\hline Lack energy to do things & 0.63 & \\
\hline Can't be bothered to do things & 0.64 & \\
\hline Take part in enjoyable activities & 0.76 & \\
\hline Symptoms and side-effects & & 0.80 \\
\hline Sleep is disturbed & 0.66 & \\
\hline Bothered by shaking/trembling & 0.58 & \\
\hline Muscles get stiff & 0.73 & \\
\hline Troubled by dry mouth & 0.72 & \\
\hline Get muscle twitches & 0.66 & \\
\hline Blurred vision & 0.56 & \\
\hline Feel unsteady walking & 0.63 & \\
\hline Get dizzy spells & 0.64 & \\
\hline
\end{tabular}

For all correlations $P<0.001, n \geqslant 160$ 
Table 3 Correlation coefficients (Spearman) between dimensions on the SQLS and GHQ-12 and HADS

\begin{tabular}{lccc}
\hline & $\begin{array}{c}\text { Psycho- } \\
\text { social }\end{array}$ & $\begin{array}{r}\text { Motivation Symptoms } \\
\text { and energy }\end{array}$ & $\begin{array}{c}\text { and side- } \\
\text { effects }\end{array}$ \\
\hline GHQ-12 & 0.66 & 0.66 & 0.66 \\
HADS & & 0.54 & 0.64 \\
$\begin{array}{l}\text { Anxiety } \\
\text { Depression }\end{array}$ & 0.68 & 0.68 & 0.48 \\
\hline
\end{tabular}

For all correlations $P<0.001, n=76$.

SQLS, Schizophrenia Quality of Life Scale; GHQ-12,

General Health Questionnaire; HADS, Hospital Anxiety and Depression Scale.

scores would be found for the GHQ-12 and HADS with all dimensions of the SQLS. These hypothesised associations were indeed found (see Table 3).

\section{DISCUSSION}

\section{Measuring quality of life}

Quality of life measurement has become an established component of health outcome assessment. It puts people with illness, including those with schizophrenia, "at the centre of inquiry, and gives due weight to their opinions"; and it addresses patients' concerns, so that "the patient may make less demands on the health sector, and indeed feel a healthier individual" (Orley et al, 1998).

We believe that a measure cannot be classified as measuring QoL unless that measure is subjective: QoL is commonly defined as "a multidimensional concept based on patients' self-report about their quality of life" (Awad et al, 1997). There is an untested assumption that people with schizophrenia cannot reliably complete selfreport questionnaires, but there is growing empirical support for the use of short selfadministered instruments with this group. Data suggest that a brief, self-administered QoL measure can yield results consistent with in-depth interviews (Greenley \& Greenberg, 1994). Furthermore, if patients can be honest about their QoL concerns without the pressure of a face-to-face interview, self-administered assessments may be more valid than interview assessments. In any event, self-report data collection is cost-effective: research consistently shows that personal interviews cost 3-10 times as much as self-report paper-andpencil approaches (Anderson et al, 1986).

\section{Reliability and validity}

Evidence is provided here for the reliability and validity of the SQLS, a novel schizophrenia-specific QoL measure. Content validity has been addressed by developing items on the basis of in-depth interviews, rather than relying on the literature or clinical scales in this field. The content of the questionnaire addresses experiences of importance to individuals with the disorder. Items that were criticised by respondents as being meaningless or ambiguous were removed. Internal consistency reliabilities of the three scale domains incorporated in the measure have been shown to be high, and all items in each scale correlate well with the overall scale score. Construct validity was explored by correlation of the scales of the SQLS with established psychiatric self-report measures and the SF-36. Results suggest that the measure is addressing areas related, but not identical, to those of previously existing measures.

We considered the appropriateness of other psychometric properties. Criterion validity assumes a 'gold standard': we do not have one. The only time one can really assess criterion validity is when a short form is compared to its parent (longer) form: i.e. comparing SF-12 results with SF-36 results. Concurrent validity assumes that two measures being compared are measuring the same phenomenon: we are not in that situation - the SQLS is diseasespecific and does not measure, or claim to measure the same concepts as measured, for example, by the SF-36. We did not attempt to measure aspects of predictive validity, which would require separate studies. We consider that test-retest is not necessary, as the $\alpha$ statistic indicates that responses are non-random and consequently reflective of an underlying phenomenon.

\section{Clinical usefulness}

The SQLS was developed to be a valid and feasible questionnaire for self-completion that addresses the perceptions and concerns of people with schizophrenia - except, of course, those too unwell to complete the questionnaire. Its main use is likely to be in clinical trials and the evaluation of clinical interventions. Evidence is presented in this report to suggest that the SQLS has desirable properties in terms of reliability and validity, and we have found the measure to have excellent acceptability and feasibility in practice. The patients taking part in the development of the instrument appeared to cover a broad range of intelligence, reading ability and educational attainment, although these attributes were not tested.

The SQLS does not purport to assess all of patients' concerns and it is not intended to replace conventional outcome measures. However, it adds important information to that traditionally collected in psychiatry. Further work is under way to test its psychometric properties in different clinical contexts and in respondents with different levels of clinical severity. It is possible to be optimistic that the impact of schizophrenia on individuals' lives can now more directly be considered when treatments for the disease are evaluated.

\section{ACKNOWLEDGEMENTS}

This work was supported by a grant from JanssenCilag via Oxford Outcomes and the University of Liverpool. South Sefton and Liverpool Research Ethics Committees gave approval.

\section{APPENDIX}

Items in the SQLS:
I. I lack the energy to do things.
2. I am bothered by my shaking/trembling.
3. I feel unsteady walking.
4. I feel angry.
5. I am troubled by a dry mouth.
6. I can't be bothered to do things.
7. I worry about my future.
8. I feel lonely.
9. I feel hopeless.
10. My muscles get stiff.
II. I feel very jumpy and edgy.
12. I am able to carry out my day-to-day activities.
13. I take part in enjoyable activities.
14. I take things people say the wrong way.
15. I like to plan ahead.
16. I find it hard to concentrate.
17. I tend to stay at home.
18. I find it difficult to mix with people.
19. I feel down and depressed.
20. I feel that I can cope.
21. My vision is blurred.
2. I feel very mixed up and unsure of myself.
19.


25. I get muscle twitches.

26. I am concerned that I won't get better.

27. I worry about things.

28. I feel that people tend to avoid me.

29. I get upset thinking about the past.

30. I get dizzy spells.

Copies of the SQLS and user's manual are available from Diane Wild, Oxford Outcomes, Bury Knowle Coach House, North Place, Old High Street, Headington, Oxford OX3 9HY; e-mail: Oxford.outcomes @btinternet.com.

\section{REFERENCES}

Anderson, J. P., Bush, J.W. \& Berry, C. C. (1986)

Classifying function for health outcome and quality-of-

life-evaluation: self versus interview modes. Medical

Care, 24, 454-469.

Awad, A. G., Voruganti, L. N. P. \& Heslegrave, R. J. (1997) Measuring quality of life in patients with schizophrenia. Pharmacoeconomics, II, 32-47.

Baker, F. \& Intagliata, J. (1982) Quality of life in the evaluation of community support systems. Evaluation and Program Planning 5, 69-79.

Becker, M., Diamond, R. \& Sainfort, F. (1993) A new patient focussed index for measuring quality of life in persons with severe and persistent mental illness. Quality of Life Research, 2, 239-25I.

Bergner, M., Bobbitt, R. A., Carter, W. B., et al (198I) The Sickness Impact Profile: development and final revision of a health status measure. Medical Care, 19 787-805.

Bigelow, D. A., Olson, M. M., Smoyer, S., et al (199I) Quality of Life Questionnaire: Respondent Self-report Version. I: Guidelines; II: Interview schedule. Portland, OR: Oregon Health Sciences University.

Boyle, G. J. (1991) Does item homogeneity indicate internal consistency or item redundancy in psychometric scales? Personality and Individual Differences, 12, 291-294.

Cronbach, L. J. (195I) Coefficient alpha and the internal structure of tests. Psychometrika, 16, 297-334.

Goldberg, D.P. \& Williams, P. (1988) A User's Guide to the General Health Questionnaire.Windsor: NFERNelson.

Greenley, J. R. \& Greenberg, J. (1994) Measuring Quality of Life: A New and Practical Survey Instrument, Paper Series 38. Madison,WI: Mental Health Research Centre.

Hattie, J. (1985) Methodology review: assessing unidimensionality of tests and items. Applied Psychological Measurement, 9, 139-163.

Heinisch, M., Ludwig, M. \& Bullinger, M. (199I) Psychometrische Testung der Munchner Lebensqualitats Dimensionen Liste (MLDL). In Lebensqualitat bei kardiavaskularen Erkrankungen (eds M. Bullinger, M. Ludwig \& N. von Steinbuchel), pp. 73-90. Gottingen: Hogrefe.

Heinrichs, D. W., Hanlon, T. E. \& Carpenter W.T. (1984) The quality of life scale: an instrument for rating the schizophrenic deficit syndrome. Schizophrenia Bulletin, 10, 388-398.

Hunt, S. M. \& McKenna, S. P. (1993) Measuring quality of life in psychiatry. In Quality of Life Assessment:

\section{CLINICAL IMPLICATIONS}

- The SQLS is a practical and acceptable method of measuring self-reported quality of life in people with schizophrenia.

- The SQLS is intended to measure quality-of-life effects of treatments for people with schizophrenia in the context of clinical trials and, by extension, in the evaluation of clinical interventions.

- Development of this simple to use, consistent and reliable instrument could help to ensure that quality of life becomes a dimension that is routinely assessed in the management of schizophrenia in a range of settings.

\section{LIMITATIONS}

There is no 'gold standard' for quality of life in schizophrenia.

Respondents were not randomly selected and may not be representative, although we doubt that this is a significant source of bias.

- Further work is underway to test the psychometric properties of the SQLS in different clinical contexts and in respondents with different levels of clinical severity.

GREG WILKINSON, FRCPsych, Department of Psychiatry, University of Liverpool, Royal Liverpool Hospital, Liverpool; BERNADETTE HESDON, MSc, Department of Neuropsychology, University of Liverpool, Royal Liverpool Hospital; DIANE WILD, MSc, Oxford Outcomes, Headington, Oxford: RON COOKSON, PhD, Janssen-Cilag Ltd, High Wycombe; CAROLE FARINA, BSc, Outcomes Research, Janssen-Cilag Ltd, High Wycombe; VIMAL SHARMA, FRCPsych, Department of Psychiatry, University of Liverpool, Royal Liverpool Hospital; RAY FITZPATRICK, PhD, Nuffield College, Oxford; CRISPIN JENKINSON, DPhil, Health Services Research Unit, University of Oxford, Institute of Health Sciences, Headington, Oxford

Correspondence: Professor Greg Wilkinson, University Department of Psychiatry, Royal Liverpool University Hospital, Prescot Street, Liverpool L69 3BX

(First received 18 August 1999, resubmitted 9 March 2000, accepted 24 March 2000)

Key Issues in the 1990s (eds S. R.Walker \& R. M. Rosser). London: Kluwer.

_, McEwen, J. \& McKenna, S. (1986) Measuring Health Status. London: Croom Helm.

Nunally, J. C., Jr (1978) Introduction to Psychological Measurement. New York: McGraw-Hill.

— \& Bernstein, I. H. (1994) Psychometric Theory (3rd edn). New York: McGraw-Hill.

Oliver, J. P. J., Huxley, P. J., Bridges, K., et al (1996) Quality of Life and Mental Health Services. London: Routledge.

Orley, J., Saxena, S. \& Herrman, H. (1998) Quality of life and mental illness. Reflections from the perspective of the WHOQOL. British Journal of Psychiatry, $\mathbf{1 7 2}$, 29I-293.

Priebe, S., Roder-Waner, U. \& Kaiser, W. (1999) Application and results of the Manchester Short Assessment of Quality of Life (MANSA). International Journal of Social Psychiatry, 45, 7-12.

Sartorius, N. (1997) Fighting schizophrenia and its stigma. A new World Psychiatric Association educational programme. British journal of Psychiatry, I70, 297.

Skantze, K., Malm, U., Dencker, S. J., et al (1992) Comparison of quality of life with standard of living in schizophrenia out-patients. British Journal of Psychiatry, I6I, 797-801.

Stein, L. I. \& Test, M. A. (1980) Alternative to mental hospital treatment. I. Conceptual model, treatment program, and clinical evaluation. Archives of General Psychiatry, 37, 392-397.

Ware, J. \& Sherbourne, C. (1992) The MOS 36-item Short-Form Health Survey. I: Conceptual framework and item selection. Medical Care, 30, 473-483.

_ , Kosinski, M. \& Keller, S. D. (1994) SF-36 Physical and Mental Health Summary Scales: A User's Manual. Boston, MA: The Health Institute, New England Medical Centre.

Zigmond, A. \& Snaith, R. (1983) The hospital anxiety and depression scale. Acta Psychiatrica Scandinavica, 67, $361-370$ 